
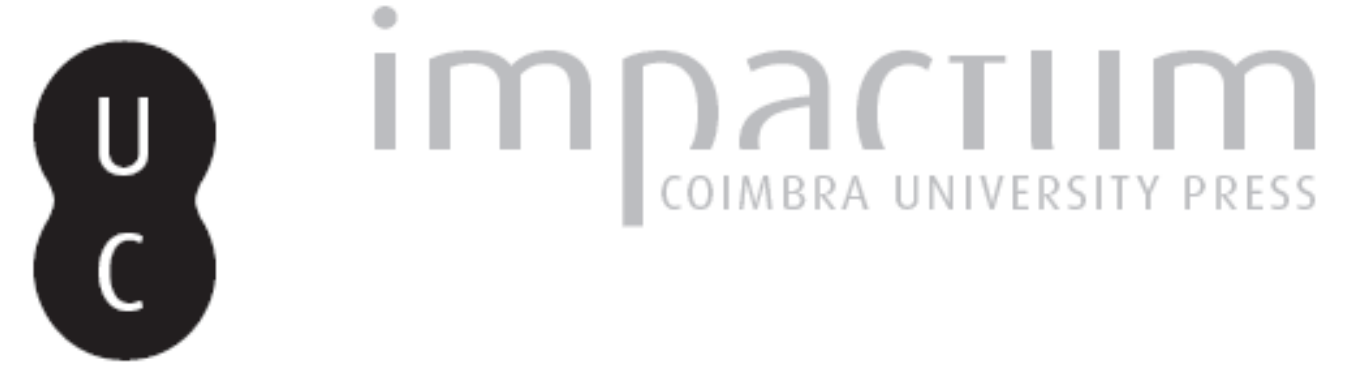

\title{
Tese de doutoramento em Geografia Física sobre movimentos de vertente e SIG
}

Autor(es): $\quad$ Rebelo, Fernando

Publicado por: Associação Portuguesa de Riscos, Prevenção e Segurança

URL persistente:

URI:http://hdl.handle.net/10316.2/40093

DOI:

DOI:https://doi.org/10.14195/1647-7723_9_11

Accessed : $\quad$ 26-Apr-2023 16:03:50

A navegação consulta e descarregamento dos títulos inseridos nas Bibliotecas Digitais UC Digitalis, UC Pombalina e UC Impactum, pressupõem a aceitação plena e sem reservas dos Termos e Condições de Uso destas Bibliotecas Digitais, disponíveis em https://digitalis.uc.pt/pt-pt/termos.

Conforme exposto nos referidos Termos e Condições de Uso, o descarregamento de títulos de acesso restrito requer uma licença válida de autorização devendo o utilizador aceder ao(s) documento(s) a partir de um endereço de IP da instituição detentora da supramencionada licença.

Ao utilizador é apenas permitido o descarregamento para uso pessoal, pelo que o emprego do(s) título(s) descarregado(s) para outro fim, designadamente comercial, carece de autorização do respetivo autor ou editor da obra.

Na medida em que todas as obras da UC Digitalis se encontram protegidas pelo Código do Direito de Autor e Direitos Conexos e demais legislação aplicável, toda a cópia, parcial ou total, deste documento, nos casos em que é legalmente admitida, deverá conter ou fazer-se acompanhar por este aviso.

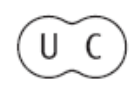




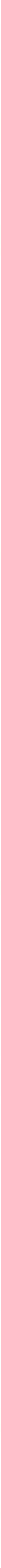


curta, mas actualizada bibliografia onde já consta 0 acima referido livro de A. DAUPHINÉ (2001). Logo na primeira página fica bem clarificado que, para Y. VEYRET, "risco" não se confunde com "aléa". " $O$ 'aléa' designa um processo físico ligadoà dinâmica terrestre" e "a 'vulnerabilidade' difere segundo o modo de relação que cada uma das sociedades mantém com o seu ambiente e segundo as práticas de gestão do risco que autorizam a sua organização e o seu nível de desenvolvimento". A conclusão é inevitável - " a geografia dos riscos não se sobrepõe à dos 'aléas"”.

Percepção e representação do risco natural, tipologia dos riscos naturais, catástrofes naturais e domínio dos riscos são os outros pontos tratados nesta introdução. Por todo o tex to se encontram exemplos de manifestações de riscos mais ou menos catastróficas, mostrando muitas vezes como é sentida a dimensão social das catástrofes - "a desigualdade face ao risco subsiste entre países ricos e países pobres e entre ricos e pobres no próprio seio dos diferentes países" (p. 15).

Seguem-se fichas em páginas duplas com "temas e documentos", de grande interesse pedagógico-didáctico. Alguns casos expostos são bem conhecidos, por terem sido espectaculares e, às vezes, relativamente recentes - inundações em Vargas (Venezuela), Limpopo (Moçambique), Dacca (Bangladesh), Oder (Polónia) e Aude (França), sismos em Kobe (Japão) e São Francisco (EUA), etc. Apesar de exemplo histórico, o terramoto de Lisboa do $1^{\circ}$ de Novembro de 1755 aparece com grande desenvolvimento (p. 60-61) verificando-se o cuidado enorme da Autora em localizar e explicar de modo simples toda a complexidade da catástrofe.

3.Climat.D'hierà demain, de Sylvie JOUSSAUME, é um livro de divulgação científica, muito cuidado, e que depois de uma primeira edição, premiada, em
1994, aparece em segunda edição nas CNRS Éditions (Paris, 1999), com uma apresentação muito agradável, bem ilustrado e bem fundamentado nas muitas questões que aborda ao longo das suas 143 páginas.

Não sendo um livro sobre riscos naturais, a verdade é que não foge deles. Logo na introdução, por exemplo, aflora as mudanças climáticas, em particular no respeitante a uma das suas manifestações mais violentas - a secura na Europa nos anos de 1989 e 1990. Mais adiante fala de ciclones tropicais e dos seus efeitos devastadores em termos de inundações. Também o fenómeno El Niño é apresentado com todas as consequências registadas em 1982-1983, tal como os efeitos "devastadores" da deflorestação em grande, por exemplo, em Madagascar. A perspectiva em que todos estes casos são apresentados é mais a do processo físico ("aléa"), do que do risco propriamente dito, incluindo a noção de vulnerabilidade. No entanto, a Autora, sempre que é caso disso, não deixa de insistir em perdas humanas.

\section{Referências bibliográficas}

DAUPHINÉ, André (2001) - Risques et Catastrophes, Observer Spatialiser-Comprendre-Gérer. Paris, Armand Colin, $288 \mathrm{p}$.

FAUGĖRES, Lucien (1990) - « La dimension des faits et la théorie du risque ». Le Risque et la Crise, Malta, Foundation for International Studies, p. 31-60.

JOUSSAUME, Sylvie (1999) - Climat. D'hier à demain. Paris, CNRS Éditions, $143 \mathrm{p}$.

REBELO, Fernando (1995) - "Os conceitos de risco, perigo e crise e a sua aplicação ao estudo dos grandes incêndios florestais". Biblos, Coimbra, 71, p. 511-527.

VEYRET-MEKDJAN, Yvette (2001) - Géographie des Risques Naturels. Paris, Documentation Photographique, n⿳0 8023, 63 p.

\section{Tese de doutoramento em Geografia Física sobre movimentos de vertente e SIG}

\section{Fernando Rebelo}

Movimentos de Vertente no NW de Portugal, Susceptibilidade Geomorfológica e Sistemas de Informação Geográfica é o título da tese de CARLOS VALDIR BATEIRA com que obteve o seu grau de doutor em Geografia Física pela Faculdade de Letras da Universidade do Porto, no passado mês de Janeiro de 2002. Na sua versão policopiada e ainda a única disponível, tem 475 páginas, com 31 fotografias e 75 figuras, entre as quais muitos mapas.
Dividida em quatro partes, tem, no total, 12 capítulos, sem contar com a "Introdução" e a "Conclusão". A primeira parte (Parte A) intitula-se "Os Sistemas de Informação Geográfica e a Cartografia dos Riscos Naturais" e tem três capítulos, mais sobre os SIG do que sobre os riscos...

A Parte B é a "Caracterização regional do NW de Portugal e da área experimental (Guimarães)". Tratando-se de um estudo sobre movimentos de 
vertente ocorridos um pouco por todo o NW, embora com um interesse especial na aplicação dos SIG à área de Guimarães, esta parte começa por apresentar a estrutura de todo o NW e logo a seguir passa para a caracterização geomorfológica do mesmo NW, culminando com a descida na escala taxonómica ao apresentar a estrutura e a geomorfologia da área amostra.

A Parte $\mathrm{C}$ tem por título "A dinâmica de vertentes no NW de Portugal" e é a maior das quatro.

No seu primeiro capítulo, "Os problemas do estudo dos movimentos de vertente na constituição de um sistema de informação geográfica" utiliza muita bibliografia para discutir o que são e quais são os movimentos de vertente, mas mostra igualmente um bom conhecimento da área em estudo, embora seja no segundo capítulo, "Apresentação monográfica de movimentos de vertente no NW de Portugal", que CARLOS BATEIRA mais salienta o trabalho de campo que realizou. Trata-se de um capítulo muito extenso onde se apresentam dez dos casos estudados. Apesar de alguns reparos de pormenor, em todo o capítulo se mostra bem a importância da ligaçăa entre geomorfologia e climatologia no sentido de explicar os processos morfogenéticos passados ou actuais. O capítulo seguinte, refere-se aos "factores geográficos de ocorrência de movimentos de vertente"; partindo dos exemplos concretos atrás apresentados, trata dos "factores de ordem hidroclimática", dos "factores de ordem estrutural", dos "factores de ordem geomorfológica" e dos "factores de ordem antrópica". Talvezos factores de ordem geomorfológica devessem ter merecido um pouco mais de atenção, maior profundidade e originalidade no seu tratamento, mas os "factores de ordem antrópica" demonstram uma boa recolha de elementos claramente observados no campo, por vezes, mesmo com a indicação do local em que foram detectados.

A ParteD, "Riscos naturais e SIG. A área experimental de Guimarães", constitui o fulcro da tese. Começa por um capítulo muito teórico, intitulado "Conceitos relacionados com os riscos naturais", por vezes discutível, dadas as numerosas citações postas lado a lado, algumas opondo-se radicalmente a outras. No capítulo seguinte, "as condições de ocorrência de movimentos de vertente e (as) unidades territoriais na área experimental de Guimarães", exemplificamse representações cartográficas, tais como o esboço das unidades morfológicas e a carta da susceptibilidade geomorfológica a movimentos de vertente, ambas para essa área e ambas acompanhadas por textos explicativos. Para o terceiro e último capítulo, intitulado "a elaboração de um SIG sobre a susceptibilidade geomorfológica a movimentos de vertente", começase por apresentar os temas em que assenta a construção de uma base de dados para a definição da susceptibilidade, a saber, a litologia, a espessura das formações superficiais, a morfologia, os declives, a rede hidrográfica e a intervenção antrópica. Descendo ao pormenor da sua explicação, acrescenta-se a tectónica (p. 402).

A conclusão, ao contrário do que poderia pensar-se, não corresponde a uma conclusão geral sobre todo o trabalho. Vem na sequência do que está escrito nos últimos capítulos desta Parte $\mathrm{D}$ e intitula-se "Conclusão e perspectivas de investigação".

Diga-se, ainda, que as 16 páginas de bibliografia que vêm no fim da tese enriquecem-na e dão muitas pistas a quem quiser dedicar-se a estudos semelhantes. Ediga-se, também, que é urgente uma versão publicada desta tese. Corrigidos alguns pormenores, sobressairá um trabalho inovador e de grande importância para a aplicação da Geografia Física. 